\title{
Females' Satisfaction of Daylight in Jeddah's Contemporary Flats
}

\author{
Alaa Shatwan
}

\begin{abstract}
In residential buildings located in Saudi Arabia, access to sufficient interior daylight is generally considered to be sufficient with that daylight made available through building window design (Dahlan and Mohamed 2010). While several studies analyse light conditions as a general parameter for urban dwellers (Boubekri 2008, Edwards and Torcellini 2002, Gou, Lau, and Qian 2013, Kim and Kim 2010), there is a lack of attention to the specific case of females spending considerable time inside homes. Moreover, the window is a socio-cultural element in Saudi Arabia and embodies a complex combination of religious, cultural, and environmental questions. This study examines females' satisfaction with daylight levels in their living spaces in middle-class residential flats in Jeddah. Twenty-three females between the ages of 20-50 who live in contemporary flats in Jeddah were interviewed. This study aims to examine female residential users engagement with daylight in their living space by addressing the general attitude of daylight sufficiency. The study provides insight into females' satisfaction of daylight provided in their daily lives through qualitative evidence. Findings strongly revealed that most flats in Jeddah city have salah with a small window facing a light well. Consequently, instead of using the salah, some females moved to other rooms that had an exterior window. However, these windows were either covered by curtains or tinted glass to provide privacy as required by Islamic culture. The lack of daylight in their domestic spaces made female residents dependent on artificial light. Currently, there is
\end{abstract}

\section{Permissions and copyright}

Authors retain copyright and grant the journal right of first publication with the work simultaneously licensed under a Creative Commons Attribution License that allows others to share the work with an acknowledgement of the work's authorship and initial publication in this journal (Attribution-ShareAlike).

Creative Commons Attribution 3.0 Unported (CC BY 3.0)

You are free to: Share - copy and redistribute the material in any medium or format. Adapt — remix, transform, and build upon the material for any purpose, even commercially. The licensor cannot revoke these freedoms as long as you follow the license terms.

Under the following terms: Attribution - You must give appropriate credit, provide a link to the license, and indicate if changes were made. You may do so in any reasonable manner, but not in any way that suggests the licensor endorses you or your use.

No additional restrictions - You may not apply legal terms or technological measures that legally restrict others from doing anything the license permits.

\section{How to cite:}

Shatwan, Alaa. 2017. "Females' Satisfaction of Daylight in Jeddah's Contemporary Flats" Enquiry 14 (1): $23-36$. no clear Saudi Arabic building code regarding the provision of daylight in contemporary flats. This study seeks to provide evidence about females' dissatisfaction with the amount of daylight within their flats, and to make a significant contribution to the gap in knowledge regarding females and daylight in Saudi Arabic culture while balancing the cultural need for a high level of privacy.

\section{KEYWORDS}

Gender, daylight, fenestration, spatial quality, Saudi culture.

\section{INTRODUCTION}

Daylight, as a natural resource, has been available over millions of years and is used globally by people as their principal source of light (Kubba 2012). More investment in the provision of daylight can help to address issues such as global warming, destruction of the ozone layer, and promote energy saving. This can be achieved by better daylight design within buildings which reduces the reliance on artificial illumination. In addition, the presence of daylight improves performance at work and human health, such as allowing better vision (Baker, Fanchiotti, and Steemers 2013). Currently, people spend most of their time indoors in buildings such as offices, houses, factories, and shopping centres, which isolates them from the natural environment (Mohelnikova 2010). Mohelnikova (2010) mentions that an interior atmosphere could be uncomfortable for occupants if it does not provide a proper quality and quantity of daylight. Natural light enhances occupants' health, mood, production and job quality. This makes biological and psychological needs as important as functional use needs (Freewan, Shao, and Riffat 2008, Freewan 2010). According to Jackson (2003), the healthiest building provides its occupants with adequate natural resources such as sunlight, natural ventilation and greenery. He argues that health issues are caused by contemporary environments which lack of natural light and access to nature in modern high-rise buildings.

The window is considered the main source for natural light, natural ventilation and a view of the outside in our built environment (Freewan 2015). Thus, window design is responsible for the amount of daylight entering an indoor area (Cammarano et al. 2015, McMullan 2012, 
Mohelnikova 2010, Baker and Steemers 2002, Szokolay 2008). However, achieving the required amount of daylight in interior spaces is not a simple task (Alzoubi and Al-Zoubi 2010). Littlefair (1991) argues that there are many design factors that affect quality and quantity of daylight in indoor areas such as window location and size, room zones, colour and materials of interior furniture (Das and Paul 2015, Littlefair 1991). Das and Paul (2015) explain that a living room needs to be exposed to daylight more than other rooms because it is the most used space of the house. Moreover, building orientation has a major role in controlling the amount of daylight inside buildings (Littlefair 1991). External to the building, the amount of light that falls on a site (i.e. residental flats) is affected by obstructions such as other tall structures.

In addition to the window, the lightwell is another source that provides daylight to building interiors. A light wellis an opening in the middle of a building from the roof to the ground. It delivers indirect daylight without direct view of the exterior environment (Freewan 2015). Kristl and Krainer (1999) studied lightwell and their results showed that using a lightwell as an additional daylight source for multi-residential flats is one of the best way to introduce natural light into a space without introducting glare or extensive heat gain. While the introduction of artificial light allows natural light entry into buidlings to be ignored, there are issues with this form of lamination. Artifical light consumes energy and increases the burden on the community (Phillips 2004).

Issues of light access are complicated by concern for privacy as the formal needs tend to be opposites. In Muslim homes, the element of privacy is highly regarded as an important factor in residential design for the purposes of protecting the female in several layers of privacy including: a) privacy between the neighbours and b) between the two genders (Othman, Aird, and Buys 2015). Visual privacy is maintained in the condition of the window through measures such as the roshan, a window screen that allows ventilation and ambient light but restricts view (Adas 2013, Alitany, Redondo, and Adas 2014).

Light quality in interior spaces were privacy is also highly prized can be seen as undefined legally in contemporary residential design in Muslim urban contexts, such as Jeddah, Saudi Arabia. Jeddah, as an urban authority, does not provide clear building regulation codes regarding the access of natural light to a building, or the size and location of windows or artificial lighting within buildings (MOJ 2015). There also seems to be little concern in this area as, to date, there are few studies investigated natural light in Saudi Arabia's contemporary architecture. Alshaibani (2000) studied the geometrical relationship between the interior space surface and window size as the main factor affecting the amount of clear-sky daylight. The study shows that the two meters side yards of the building, which were intended to produce ventilation for the building led to extensive heat in interior spaces during the summer (see Figure 1). Additionally, the exterior windows were covered with curtains most of the time to maintain inhabitants' privacy, which is important in Islamic culture and to keep out sharp sunlight (Dahlan and Mohamed 2010).

According to Shatwan and Carta (2017), vernacular architecture in Jeddah clearly considers the privacy between people inside the home and street pedestrians by the use of roshan. However, modern architecture in the city fails in this regard by using glass windows in all residences, which is an implementation of western design. It is not only the façade design which has changed with Western design influences. The traditional space for a nuclear family used to be private rooms and bathrooms in an extended family home with a shared reception, kitchen and living spaces allowed interaction with other family members. In contrast, contemporary architectural space planning has changed the notion of privacy to focus more upon providing a nuclear family with a private house or flat, instead of merely a room in a large family home.

According to Islam, a female must have a male guardian whose approval is required for many life decisions. In some families, men do not allow women to work in a different city or in certain jobs due to the possibility of coming into contact with other men from outside the family, or they may want their wives to remain solely as housewives (Abukalid 2004). In this case, a women's job opportunities will be very limited as men control this area (Syed et al. 2013). One result of this social condition is that women in the Middle East spend most of their time inside their homes (Alawad 2017). Most activities of women concern their family needs at home; therefore, the home should provide a healthy and enriched environment for long term use, especially in regards to daylight. Given the considerable limitations of the provision of daylight in Saudi Arabia when considered in relation to privancy and revealed by various studies, this study aimed to investigate females' satisfaction regarding daylight levels in the living rooms of contemporary flats in Jeddah. As noted previously, the living room requires the most light due to its central role in family life.

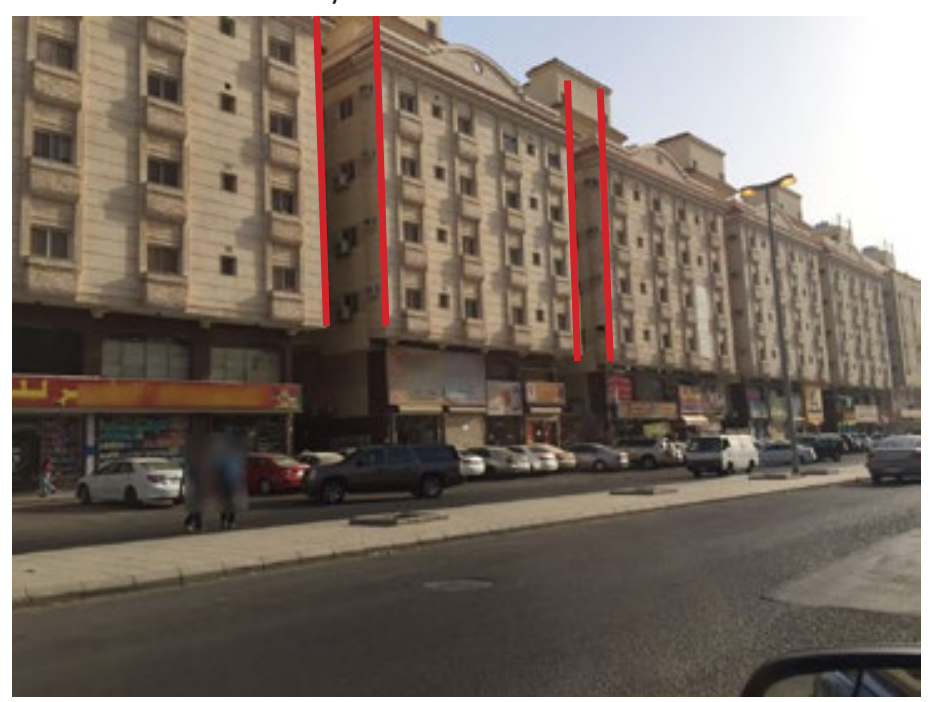

Figure 1. Small gap between buildings in Jeddah

\section{METHODOLOGY}

This study included 23 Muslim Saudi Arabic females (aged 20-50 years) with various marital status (see discussion later and Table 7). All participants live in contemporary flats in Jeddah city (Figure 2). Jeddah city is Saudi Arabia's largest port and the most important commercial city in the kingdom. It is located in the Red Sea coast in the western 
part of the country. Climate in Jeddah is considered warm with low precipitation in winter and hot with high humidity in summer (Khodeir et al. 2012). The participants were selected using a snowballing technique engaging social networks. The criteria of study focused on females as Saudi females-especially non-employed women-tend to stay at home during the daytime. Also, female employment is still not accepted by some married men (Elamin and Omair 2010). Jeddah city has the highest number of rental flat buildings in Saudi Arabia (MOJ 2015). The research focused on flats because it is a rental type of residence, so the inhabitants are not allowed to make changes in flat design. This is contrasted with the freedom of spatial revision that occurs in villas, which are generally owned in Jeddah. In addition, the building regulations for flats are different from those of houses. For example, spacing between residential flat buildings should be two metres between the side and back of each building. However, spacing between villas should be four metres for each side of each villa (MOJ 2015).
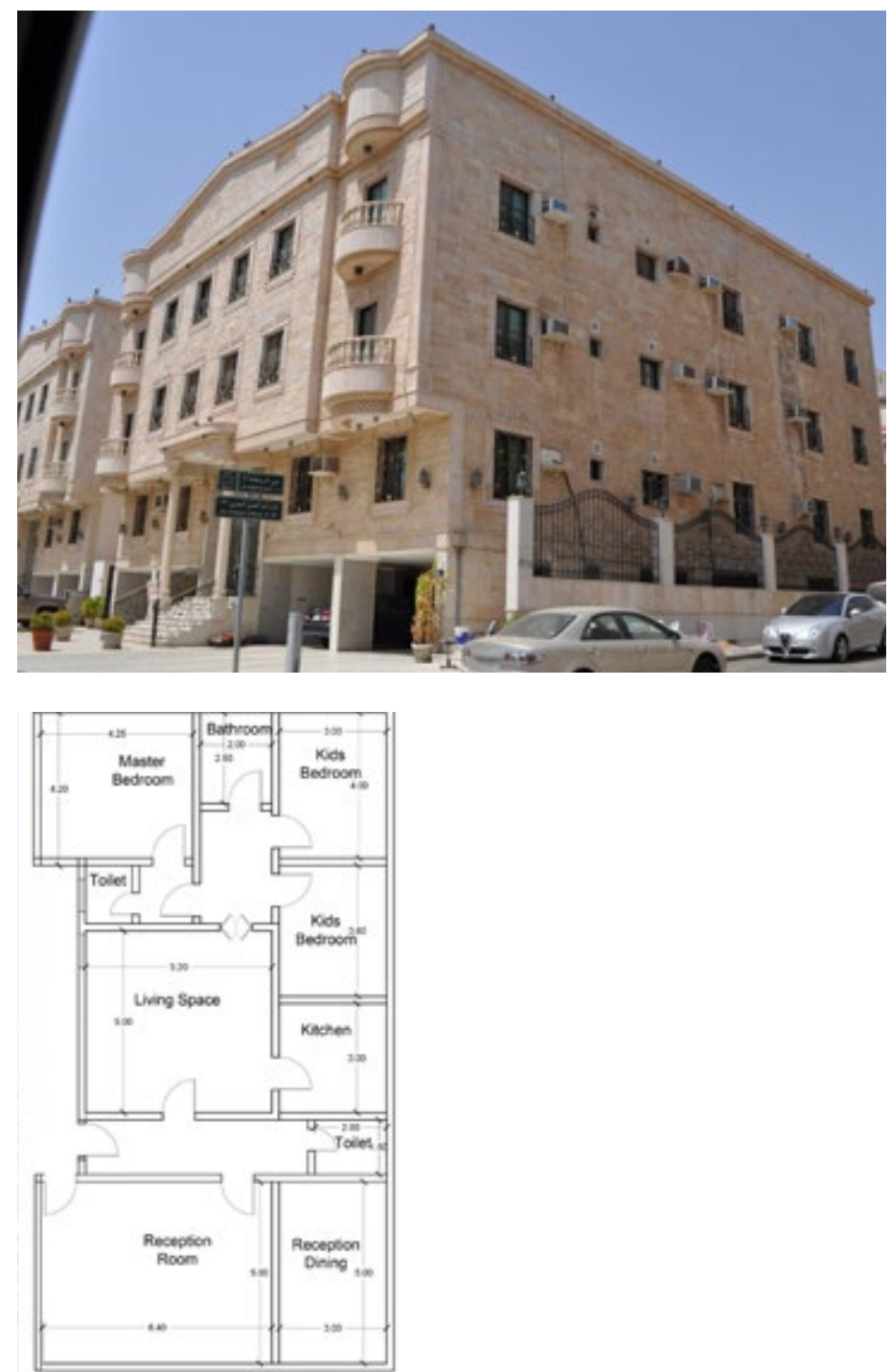

Figure 2. Contemporary flat building and floor plan
The sample size was selected based on the literature review, which demonstrated that 20 to 30 respondents provide an adequate and appropriate sample size in a study comprising in-depth interviews (Creswell 1998, Mason 2010). Furthermore, qualitative analysis requires a smaller sample size compared to quantitative analysis in order to avoid data saturation, which occurs when the participants are no longer providing any additional perspectives or information. In qualitative studies, in-depth interviews aim towards further understanding of a phenomenon and do not aim for generalisation of the findings (Charmaz 1990). In this study, interviews stopped after 23 participants had been interviewed; at this time, the researcher started to recognise that answers were becoming repetitive and concluded that enough data had been collected. A qualitative research methodology was employed in this study due to a lack of current statistical data and difficulties in collecting new statistical data in an Arabic society (Zamberi Ahmad 2011).

1. On what floor is your flat?

2. Where in the flat do you stay most often during the daytime? Why?

3. At what time do you sit in the living room?

4. What activities do you do in the living room?

5. Does the living room window face the light well or the exterior?

6. How important is daylight and the window location for you at home?

7. In how many flats did you live before moving to this flat?

8. Did they share similar daylight levels and window design?

9. How are you exposed to daylight?

10. Would you prefer to have the living room in another room of the home? Why?

11. What is the major element that bothers you with the window? Why?

12. What type of glass is used in the window?

13. Does your living room window provide enough natural light?

Figure 3. Example of questions that were used in semi-structured interviews.

Semi-structured interview questions were developed by the researcher (Figure 2). Interviews took place in the summer period (May 2016 until August 2016) as this has the longest sunlight period compared to other seasons. Current presence of sunlight was considered pertinent to the topic of the study and would allow participants to reflect on a sense of satisfaction with the daylight in their flats. The interviews took place in the participant'scurrent residence or at their parents' homes. Each interview lasted between 30-50 minutes, based on the participant's perceptions on the subject. An explanatory introduction was given at the start of each interview. Full transcripts were written after each interview in addition to the author's comments. Qualitative workbench software (Nvivo) was used to analyse data as it can allow access to deep analyses in rich text-based contexts and is considered an industry standard for analysing interview data. 
Interviews included a discussion about participant's lifestyle and daily activities. In order to gain a better understanding of the importance of living rooms as the most used space, participants were asked about their early morning activities, followed by their tasks throughout the day. Then, the participants were asked what they did in each hour. As not every participant was able to explain well their day-to-day routine, the researcher helped them with key words for better communication, including examples, to facilitate the interview process. This helped the researcher to understand the type of activities female perform in the living room and time spent on each activity.

Several points of interest arose during the interview process. First, many of the participants answered questions about their personal life in an evasivemanner as they perceived the questions regarding their private sphere as intrusive. The participants proved reluctant to share this part of their lives as it was considered intimate and, as such, to be kept separate from "foreigners". Second, when the researcher mentioned home layout design generally, and daylight specifically, the fluency and enthusiasm of the respondents' speech changed dramatically; they started to talk loudly and did not want to stop. The way they discussed daylight expressed their interest in the topic and, after suffering from a certain issue, they had finally found someone who shared the same thinking. Some participants wanted to elaborate on their issues with light quality in rental flats by comparing their current flat with their parents' villas, stressing the increased happiness with daylight in the villas. The participants further mentioned the lack of interest among the men in the family regarding this issue including the effect on their relationship. Some participants who studied abroad discussed how their homes in the United Kingdom or United States more strongly addressed their needs for daylight. The interviewees claimed that their homes should be designed by somebody able to understand the nature and details of their needs and daily use. They suggested that only other females are in the position to appreciate in a comprehensive manner such needs. It was claimed that males have a completely different perception of the use of interior spaces in the observed flats.

The researcher decided to interview participants during the daytime in their homes. The choice to focus on women was considered important as this part of the population is not entirely considered in the statistics or included in the design guidelines offered by the government. In addition, men are allowed more variation in their daily lives, existing the home to go to mosque five times a day as part of the religious customs. The journey from home or work to the mosque exposes the male to direct sun on the street. Even in an educational setting, most women are not exposed to direct sunlight as school or university courtyards are covered with a ceiling for privacy and windows are either covered with curtains or tinted glass. Accepted extra-residential female activities, such as shopping or visiting relatives, occur in the evening or at night for the majority of the population as an aspect of modern culture. The hot summer climate (30-50 degrees Celsius) in Middle East countries is a major restrictor of outdoors activity; furthermore, there is a lack of appropriate facilities for these types of activities, such as parks (Benjamin and Donnelly 2013). Consequently, females are seldom exposed to sunlight outside of their home situation.
Considering the points above, this paper will discuss females' perceptions of daylight and flat design in relation to their comfort.

The interview findings are subsequently discussed according to the points listed below.

$\begin{array}{ll}\text { - } & \text { Living space salah and light well window } \\ \text { - } & \text { Daylight and building codes } \\ \text { - } & \text { Wemale privacy and daylight in living room } \\ \text { - } & \text { Privacy and roshan } \\ \text { - } & \text { Daylight and well-being } \\ \text { - } & \text { Female satisfaction in contemporary flats } \\ \text { - } & \text { Female rights in choosing home } \\ & \text { Comparison between villa and contemporary flat }\end{array}$

\section{LIVING SPACE SALAH AND LIGHT WELL WINDOW}

The in-depth interviews with Saudi female showed that living space (salah) or the living room is the most used space for all females for their daily activities. Though the kitchen is used during different times of the day, the majority of participant's time is spent in the living space. Since females stay at home, they need to live in homes that fulfil all their psychological and physiological needs. A living space with a small window facing a lightwell as a main source of light does not provide adequate quality light and, thus, is clear evidence of the lack of studying habitants' needs in architectural design. According to the results from interviews with participants, it was apparent that most flats in Jeddah city have salah as shown in Table 1. Salah is an open living space located at the flat's entrance and, as such, it is the first space encountered when entering the flat (Figure 2). The majority of participants who had a salah with a window facing the lightwell claimed that the lightwell is not a source of daylight (Table 2). However, this finding is inconsistent with previous study that consider light well as an additional daylight source for multi-residential flats could be seen as a good solution to provide natural light without glare or extensive heat (Kristl and Krainer 1999). On the other hand, the majority of participants from the first to third floors complained that they do not use the salah or the open living space as the window facing the lightwell due to a lack of light quality (e.g. morning light looks like sunset, or constant twilight). This issue was raised in most interviews, prevalent with participants living in flats on the ground and the third floors. One of the participants was surprised to hear that research proved that even if a lightwell does not provide enough daylight, at least it makes you aware of daylight (Lam 1992), Vischer 1989). She asked with a shocked face pointing at the window "do you see any daylight?". This interview was taking place in summer from 12 to 2 p.m., when the sun is very bright in the city.

The lightwell is a design element inspired by Western architecture allows for a higher density floorplate and can be applied on building with more than two floors (Kristl and Krainer 1999). The vernacular Saudi architectural courtyard was the traditional element that provided daylight and ventilation to buildings and is very similar to the concept of a lightwell. This shows that when architects practiced vernacular architecture in designing courtyards, they studied climatic and cultural 


\begin{tabular}{|l|l|l|l|l|l|}
\hline \multicolumn{1}{|l|}{} & $\begin{array}{l}\text { Age } \\
50-59\end{array}$ & $\begin{array}{l}\text { Age } \\
40-49\end{array}$ & $\begin{array}{l}\text { Age } \\
30-39\end{array}$ & $\begin{array}{l}\text { Age } \\
20-29\end{array}$ & $\begin{array}{l}\text { To t a I } \\
{[23]}\end{array}$ \\
\hline 1. Living room & 0 & 2 & 2 & 1 & 7 \\
\hline 2. Living space (salah) & 4 & 2 & 6 & 5 & 16 \\
\hline
\end{tabular}

Table 1. Number of flats that has salah in the flat's major layout.

\begin{tabular}{|l|l|l|l|l|l|}
\hline & \multicolumn{1}{l}{ Age } & Age & Age & Age & Total \\
& $50-59$ & $40-49$ & $30-39$ & $20-29$ & {$[23]$} \\
\hline No daylight & 1 & 4 & 7 & 4 & 19 \\
\hline Enough daylight & 1 & & 2 & 1 & $4 *$ \\
\hline * (not facing light well) & & & & & \\
\hline
\end{tabular}

Table 2. Daylight level in salah.

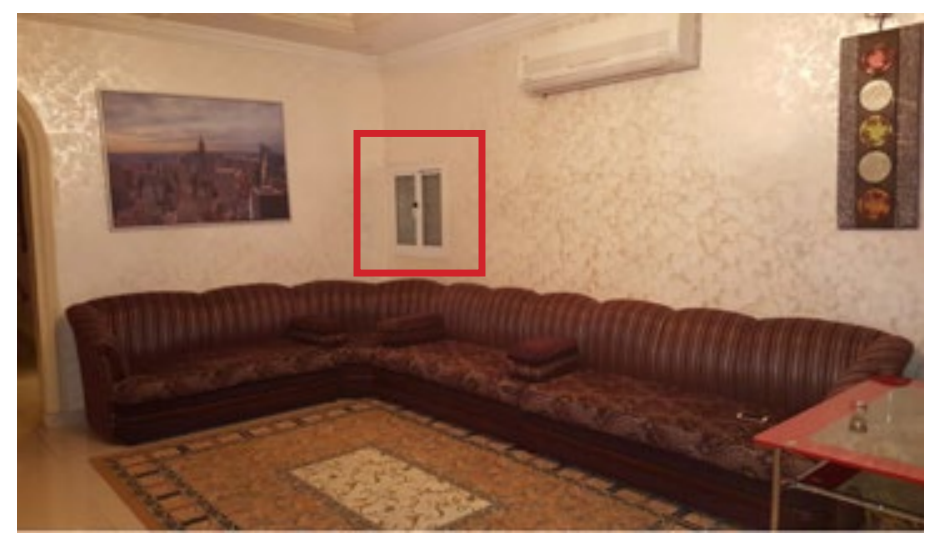

Figure 4a. Light well windows in the living space. (third floor).

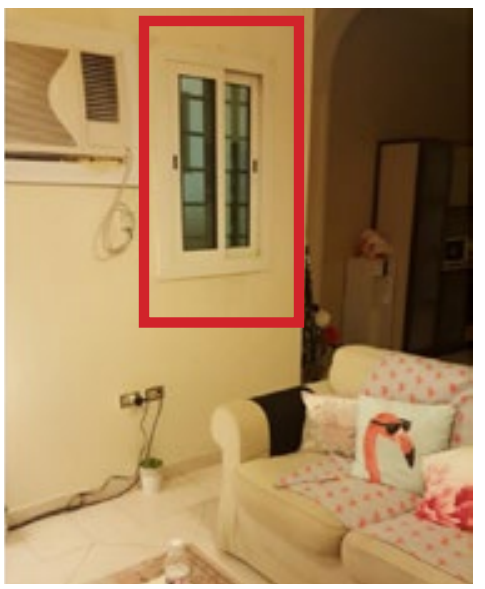

Figure 4b. Light well windows in the living space. (first floor). needs, thus providing privacy too. On the other hand, a lightwell is a Western variation of the courtyard found in modern design that is implemented in Arab countries but does not address its suitability for Arab culture in general or Saudi culture specifically. Kultermann (1999) claims that most modern buildings in Arab countries show Western design elements. According to Asfour (1998), one of the major issues in contemporary Arab architecture lies in the fact that these design elements are details and forms copied from Western buildings and pasted into Arab contexts with great disregard of the differences between contextual aspects and cultural values underpinning those elements.The lightwell is one of those elements referenced by the previous claims by Kuhlmann (2014) and Asfour (1998).

Three issues stem from lightwells, namely that they do not provide daylight, they transfer bad smells and noise and they do not allow people to know the time of day. For lightwell windows, privacy does not concern only visual privacy but also acoustic privacy; this is one of the issues that was introduced by the participants as a reason for not using this space. This issue was also raised by Hashim and Rahim (2010) who, after interviewing people in their homes, found that sound privacy was lacking in Malayan homes. They noted that this issue arose because of closely adjoining and small homes. However, the use and efficiency of the light well in providing daylight depends on its architecture: the narrower and longer it is, the less the illuminance it provides. Freewan, Gharaibeh, and Jamhawi (2014) also showed that the design of the lightwell opening could be a factor in the daylighting performance of the light well. Providing occupants with a light well window shows not just a lack of understanding of cultural needs, but also does not consider sustainability which is a major element in architecture (Edgar and Lahham 2008, Goell 2007).

A lack of daylight in a space will make users rely mainly on artificial light. This is observed by some participants who mentioned that they have to keep an eye on the clock to know the time of day or they can know it from the prayer sounds that come from nearby mosques. Some researchers claim that excessive heat from exterior wall windows increases energy consumption through the extensive use of air conditioning (Gul and Patidar 2015, Kreith and Goswami 2016). Similarly, the author posit that having a living space with windows facing a light well is a major factor for energy consumption as occupants have to turn on artificial light starting at the time they wake up. This will lead to larger levels of energy consumption as artificial light consumes a considerable amount of energy in a building (Batterjee 2010, Ghisi and Tinker 2005) that can be as hight as 25-40 percent (Krarti 2000). Increasing access to daylight will necessarily and significantly decrease energy consumption (Crisp et al. 1988).

\begin{tabular}{l|l|l|l|l|l|l|}
\hline & \multicolumn{1}{l}{$\begin{array}{l}\text { Age } \\
\end{array}$} & Age & \multicolumn{1}{l}{ Age } & Age & Total \\
& $50-59$ & $40-49$ & $30-39$ & $20-29$ & {$[23]$} \\
\hline Living in bedroom & & $\mathbf{1}$ & $\mathbf{2}$ & & $\mathbf{3}$ \\
\hline Living in guest reception & & 1 & & & 1 \\
\hline Living in salah & 3 & 2 & 4 & 5 & 13 \\
\hline Living room & & 3 & 2 & 1 & 6 \\
\hline
\end{tabular}

Table 3. Number of women who use salah or other rooms as living room. 
Since most female do not use a living space with a window facing a lightwell, the studyinterviewed female who substituted another room in their flat to be their living room (Table 3). Surprisingly, females' complaints about the lack of daylight did not end here. A new reasons started to be raised about exterior wall windows that reduce daylight levels inside the rooms as will be discussed in the coming points.

\section{DAYLIGHT AND BUILDING CODES}

The Saudi building code requires that all habitable areas should have natural light access or artificial lighting (MOJ 2015); however, the researcher interviewed three participants with living spaces that had no windows at all. This suggests that the relationship between natural and artificial light has not been clearly set in the code. The flats in Jeddah have small spaces and few windows, which offset the perception of inability to afford a normal living. Based on the idea that Saudi females would want large living spaces that are well-lit, these results depicts that flats present a poor quality of light condition in the interior space. The living space in these flats conveys a claustrophobic feeling, generating an atmosphere that resembles a "jail", as expressed by one participant, for it isolates the inhabitants from the outside world. One of the participants

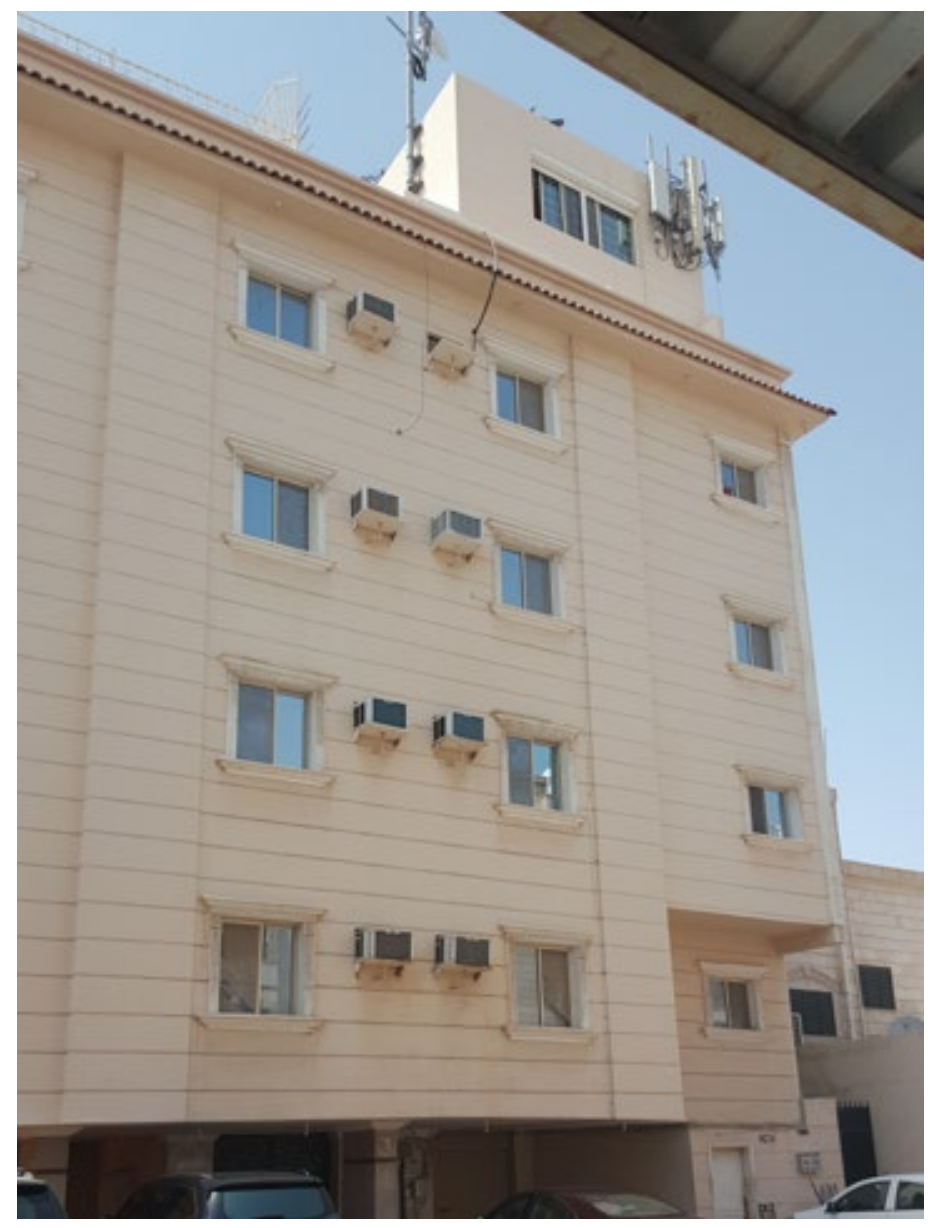

Figure 5. Flats in high-income district in Jeddah who lives in such a flat mentioned that: "We are living in the sun land we have a lot of sun. However, women have severe psychological and physical issues due to not seeing the sun".

Siddiqui and Kamfar (2007) linked between low-income areas and the proximity of buildings to one another. However, this point is not valid because building regulations do not vary from one neighbourhood to another, but rather only between different types of building. Therefore, even middle-income families and above can suffer from the same issue if they live in flats. According to the municipality, the gap between buildings should be no less than two metres for the sides and backs of apartment buildings (MOJ 2015). This rule must be followed in all neighbourhoods, regardless to property value or income level. The issue of building proximity is still present in districts populated by rich families in high-rise buildings (as shown in Figure 5).

\section{FEMALE PRIVACY AND DAYLIGHT IN LIVING ROOM}

Privacy controls major parts of home design in Saudi Arabia ( Mofti and Balto 2013). The design of residences is usually a reflection of the principles of privacy, modesty and hospitality (Othman, Aird, and Buys 2015). In most Muslim houses, the conservation of privacy is a vital factor and this is reflected in the screening for view tomaintain visual privacy for the protection of the female members of the family (Mortada 2003). In this context, a window is designed in relation to privacy rather than access to light and visibility. This raises an argument that exterior walls windows are controlled by cultural beliefs rather than environmental needs. For instance, most windows are small in flats in Jeddah. Some windows are covered with either wood board or darkcoloured reflective papers for privacy. These small windows are unable to provide sufficient light in the house and do not observe privacy as a factor among Saudi Arabians, especially among female.

Privacy is defined differently in different parts of the world but there is a uniqueness to the interpretation of privacy in Saudi culture (AlHumaidi 1996) . Rather than being an issue of physical access, privacy in Saudi culture is the protection from neighbours' eyes. Thus, the issue of privacy as a design challenge in flats in Jeddah which must balance between healthly environments physically but secluded environments culturlaly, something addressed through the finding of this research and explains the presence of the curtain.

Females requiring privacy in the presence of an external window have to open one side of the window and make sure it is covered with a curtain (Figure 6).This solution does not make home occupants' feel comfortable since dust enters when opening the window; this is, however, the only solution. All participants are not satisfied with this issue, but they do not have the right to change it. As mentioned by participants, this is done by conservative stakeholders who want to create privacy in interior spaces. However, female claim that this is not the right solution because it blocks daylight totally. Therefore, the design of windows should not only consider upholding privacy or protecting users against hash impacts of weather such as dust also the idea that light need to be penetrative in the entire intended rooms. Susilawati and Al Surf (2011) and Al-Jamea (2014) argue that the reason behind dissatisfication among Saudi female 
with the contemporary housing designs is because the roles of windows are diminishing and their traditional usefulness is vanishing.
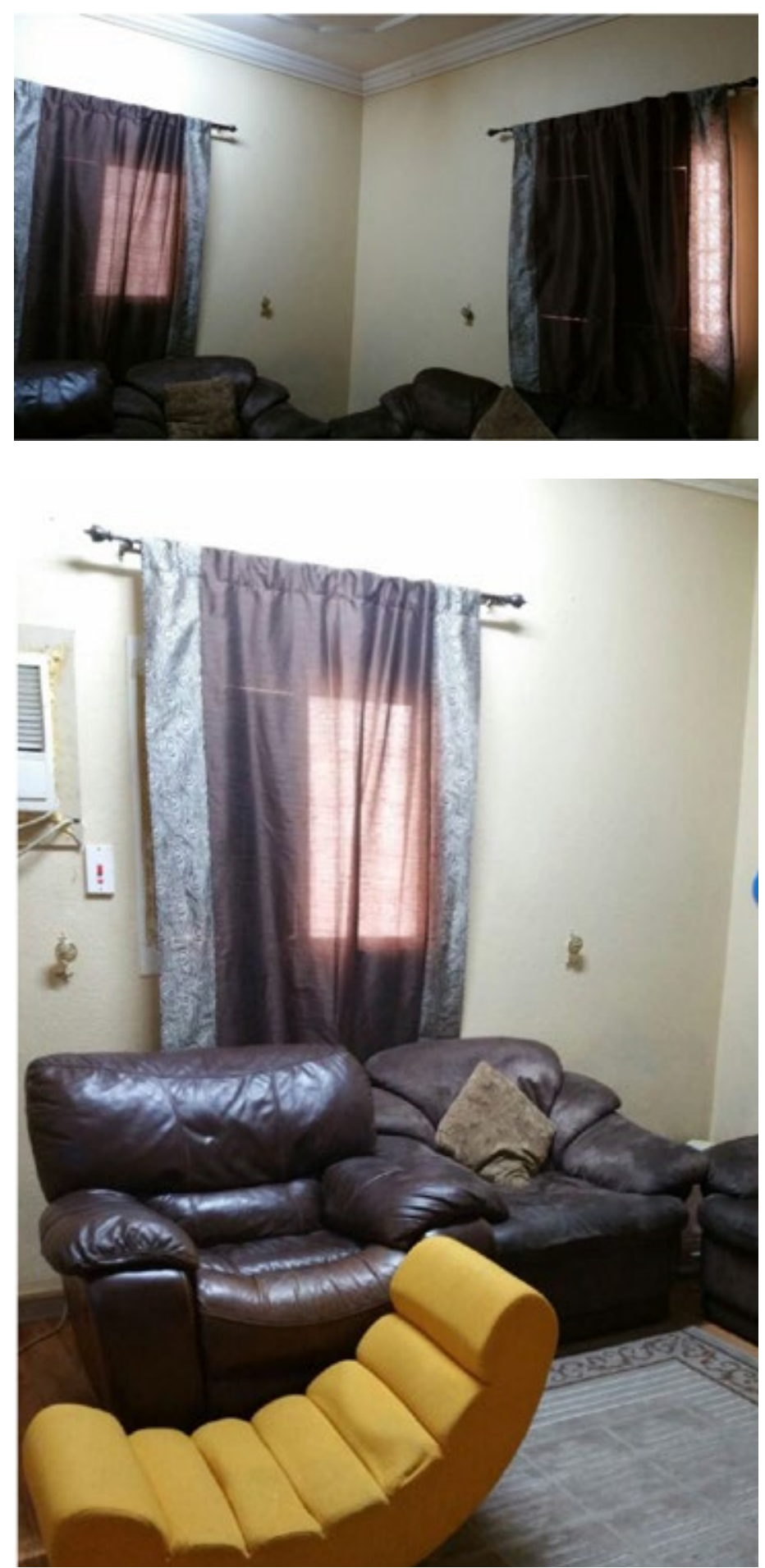

Figure 6. Window covered with black paper for privacy.
The reason for blocking glass with private elements is due to the small gap between buildings where people could be seen by neighbours. The findings of this section raised a question about why municipality rules set two metres to be the minimum gap between buildings. Since two metres is the minimum, it is actually the only distance found between buildings as all stakeholders wish to maximize landuse. On the other hand, females find this small gap insufficient in terms of privacy. After interviewing participants, it is found that the municipalities who set building codes, architects who design the space and people who use the space are thinking in different ways. There is however no clear study on why there exists differences between the users and designers of the living space and how this difference can be solved. This tension between users and planners needs to be addressed. For instance, Dahlan and Mohamed (2010) argue that a two metre gap between buildings in municipality regulations is more than enough as it provides extensive sun and heat inside a home. They go on to assert that the two metres was set as building code to provide daylight, but that light also caused significant heat through solar gain within the interior spaces. In critique to this position, the 20 participants who had small or medium-sized windows claim during the interviews that their flats lack daylight due to various reasons, one of which is the small gap between buildings (Figure 6). Similarly, the three participants who live on the top floors (Figure 9 and Figure 10) with huge windows confirmed their satisfaction with the amount of daylight in their living space. Therefore, the findings of this study disagrees with Dahlan and Mohamed (2010) and argues that the gap between buildings should be increased to enhance daylight and provide privacy, or a new design solution should be studied to solve this issue.

\section{WIDOW DESIGN AND DAYLIGHT}

There are many issues found in exterior window design that create a lack of daylight in terms of window size, glass type and location. All participants from the first to third floors have one window in the living room. Only three participants have two medium-sized windows because they used one of the corner bedrooms or reception rooms to be their living room. However, they are not satisfied with the daylight because they share the same issue as all other women in that the window is facing neighbours with a very narrow gap that does not exceed four meters total. One participant with this case mentioned:

"I always find this as a major issue not just for daylight but also the view. I think $50 \mathrm{~m}$ is the minimum distance that should be between buildings. I hope that a person who holds a main position that her voice could be heard to add this 50-m rule".

The claim of this woman is similar to the others. This clearly suggests that female voices are not heard. Additionally, participants claim that the issue is the type of window. It is either frosted or covered with black paper for privacy. On the other hand, transparent glass is an issue by itself because it must be covered with a curtain all the time for privacy. Therefore, the author argue that window size is not a critical an issue for the lack of daylight as glass type. The other option for daylight is the balcony. Idris (2001) found that balconies are not used in university 
staff's modern flats in Riyadh. Although the flats examined in this had two balconies, all occupants shared the same response that they do not sit on them because they are narrow, small and lack privacy. They use them as storage. Similarly, some participants in this current study had a balcony in previous flats; however, the majority did not use it because it was not private. For instance, one participant covered it with a wall and added it to the room. Other women used it as storage or for drying clothes. Two participants mentioned that the balcony in their flats is covered totally with frosted glass for privacy. The issue is that it blocks daylight reaching the room from the window. There is one participant who lived in a flat with a balcony that is covered only up the height of a human; the top part is open. This female enjoyed siting on it in the morning because it provides daylight and privacy. This solution was recommended by seven female who dream of having a balcony.

\section{PRIVACY AND ROSHAN}

To discuss privacy and daylight, the researcher questioned participants about roshan. The question was if participants preferred a vernacular window in Jeddah over a contemporary glass window. The finding was a surprising answer that disagrees with most of the previous papers that support roshan. The majority of the data in this study contradicts the position that roshan provide enough daylight with ventilation and privacy (Abu-Ghazzeh 1994, Adas 2013, Al-Jawahrah 2002, Al-Murahhem 2008, Hariri 1991, Salloum 2013).

There are also some points of agreement with previous findings. As a cultural element, the roshan is not valued and considered as "oldfashioned" (Al Murahhem 2008). In this study, 11 participants discussed the aesthetic part of roshan (Table 4), its pattern and how it reflects Islamic design. One participant mentioned that she would implement it in the interior decoration but not the exterior. In Islamic architecture, light is used to create interior decorative patterns (Al Surf, Susilawati, and Trigunarsyah 2012). This point is also found in roshan with its pattern design. Only 3 participants mentioned that it provides daylight and ventilation, as shown in Table 2 with the rest of the group having little knowledge of the roshan.

According to Samuels (2010), roshan is no longer employed due to its cost and manufacturing time. While this is true, there is another additional important reason: roshan is not required today culturally by people in Jeddah. Only two out of 23 female mentioned that they enjoyed looking at the street from roshan. The majority of females, whether they live in a home with roshan or not, rejected the idea of having roshan in their flats (Table 5). Females who lived in a flat with roshan claim that it does not provide enough daylight. The light enters from the small holes and gives dim light. They used to sleep in the afternoon while the roshan is open, but they used to close it for another reason-privacy. Out of 6 women who lived in a flat with roshan, two women claimed that they used to be observed by pedestrians especially since they are on the ground and first floors. This finding disagrees with that of Salloum (2013) who discussed roshan's small opening function for providing daylight and privacy. The rest either prefer a modern glass window or find roshan difficult to clean and dust, as shown in Table 6. There are two participant who disagree with the idea of roshan and privacy. One participnt mentioned: "I went to a hotel with roshan. I did not feel comfortable at all. It is like jail. It blocks you from the exterior. I would not repeat this experience. I prefer a glass window". From the analysis of this section, it shows that roshan is not a recommended type of window anymore in the coming generation. It also shows a finding that is opposite to that of other papers. Roshan does not provide enough daylight in an interior space and only provides privacy if on a high floor. This shows that the idea of roshan is not recommended by most females.

\begin{tabular}{|l|l|l|l|l|l|}
\hline \multicolumn{7}{|c|}{$\begin{array}{l}\text { Age } \\
50-59\end{array}$} & $\begin{array}{l}\text { Age } \\
40-49\end{array}$ & $\begin{array}{l}\text { Age } \\
30-39\end{array}$ & $\begin{array}{l}\text { Age } \\
20-29\end{array}$ & $\begin{array}{l}\text { Total } \\
{[23]}\end{array}$ \\
\hline $\begin{array}{l}\text { What you know about roshan? } \\
\text { Beautiful }\end{array}$ & 2 & 0 & 4 & 5 & 11 \\
\hline $\begin{array}{l}\text { Provides daylight } \\
\text { \& ventilation }\end{array}$ & 1 & 1 & 0 & 1 & 3 \\
\hline
\end{tabular}

Table 4. Women's answers about roshan.

\begin{tabular}{|l|l|l|l|l|l|}
\hline \multicolumn{7}{|c|}{$\begin{array}{l}\text { Age } \\
50-59\end{array}$} & $\begin{array}{l}\text { Age } \\
40-49\end{array}$ & $\begin{array}{l}\text { Age } \\
30-39\end{array}$ & $\begin{array}{l}\text { Age } \\
20-29\end{array}$ & $\begin{array}{l}\text { Total } \\
{[23]}\end{array}$ \\
\hline \multicolumn{2}{|l|}{ Want to implement roshan? } \\
\hline yes & 0 & 2 & 0 & 0 & 2 \\
\hline no & 4 & 2 & 9 & 6 & 21 \\
\hline
\end{tabular}

Table 5. Number of women who want to have roshan in their flats.

\begin{tabular}{|c|c|c|c|c|c|}
\hline & $\begin{array}{l}\text { Age } \\
50-59\end{array}$ & $\begin{array}{l}\text { Age } \\
40-49\end{array}$ & $\begin{array}{l}\text { Age } \\
30-39\end{array}$ & $\begin{array}{l}\text { Age } \\
20-29\end{array}$ & $\begin{array}{l}\text { Total } \\
\text { [23] }\end{array}$ \\
\hline \multicolumn{6}{|c|}{ What issues do you have about roshan? } \\
\hline Weak daylight & 2 & 2 & 5 & 0 & 9 \\
\hline Introduces dust & 0 & 0 & 5 & 0 & 5 \\
\hline Difficult to clean & 1 & 2 & 0 & 0 & 7 \\
\hline Not private & 1 & 0 & 1 & 0 & 2 \\
\hline
\end{tabular}

Table 6. Issues of roshan that are mentioned by participants.

\section{DAYLIGHT AND WELL-BEING}

Daylight has great impact on well-being of both genders (Parmar 2016). However, due to cultural and religion demand for privacy in some countries, studies have investigated the lack of daylight exposure and its effect on adult female health, such as vitamin D deficiency. Christie and Mason (2011) undertook semi-structured interviews with 17 university students in Prince Sultan University and found that the majority are not exposed to daylight outside their homes as their bodies are entirely covered with Abays. This type of clothing, which comprises long black 
material covering the whole body, does not allow the body to absorb daylight (Alsuwaida et al. 2013, Naeem et al. 2011). Similarly, a study done in Jordon examined volunteers from both genders regarding their body absorption of vitamin $D$ from sun shows that women who were $\mathrm{Hijab}$, clothing similar to Abaya, have significant vitamin D deficiency in comparison to those who do not wear Hijab or to men (Mishal 2001). The second reason is that homes do not allow female exposure to daylight in a private setting, except for those who live in houses with high walls gardens. However, even those who live in such houses reported insufficient exposure to daylight due to the heat (Christie and Mason 2011). According to Siddiqui and Kamfar (2007), a considerable number of female students in the western region of Saudi Arabia have vitamin $D$ deficiency. They go on to assert that these students, who do not gain exposure to sunlight, are within the low-income demographic. The authors suggest in conclusion that living in low-income neighbourhoods with homes close together could be the reason for the lack of sunlight in residences (Siddiqui and Kamfar 2007). However, this study's finding of the lack of formal differentiation between low-income and high-income building regulations and setback contests this finding. Rather, this study found that lack of exposure to sunlight within buildings is also a common issue in middle-income families.

In addition to adults, daylight is an important factor in improving the health of children. Mothers with young babies on all floors, except the roof, said that they cared about daylight and the physical health of their children. One participant explained that in her previous house, there was not enough lighting and access to natural light to enable her daughter to grow. Therefore, she had to move into a new flat where a balcony was available for her daughter to be able to be exposed to daylight. Other participants mentioned that they suffer from bone issues, and doctors advised them to get exposure to the sun; however, they cannot since they spend all their time in a flat with weak daylight. The majority of females care about daylight for their psychological comfort. Ten of them said they feel depressed when spending the morning in the living room because they do not really feel it is the morning. Their feelings vary from bored to depressed.

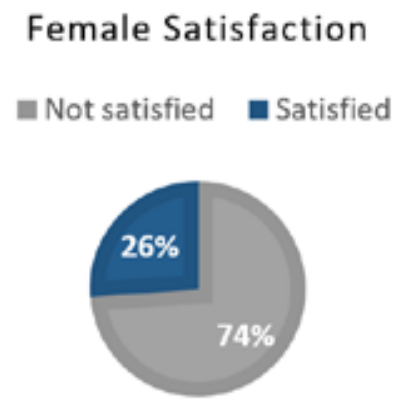

Figure 7. Diagram to show Females' satisfaction with daylight level in living room.
Most of the answers for 17 women show that they are not satisfied with their flats in regards to daylight issues. According to Gamboa (2008), contemporary homes for middle- or low-income families do not fulfil occupants' needs in general. Similarly, Salama (2006) showed that the inhabitants of flats have needs in terms of their culture and environment and these must be considered in any type of home, even affordable homes.

However, it is not just in affordable homes that these issues persiste but also in middle-class rental homes as only $26 \%$ of participants showed satisfaction according to their answers as shown in Figure 7. Three of them live in roof flats with big windows and a big flat according to family members. One participant lives in a flat with enough daylight since there is no building close by next to it. Although the living space window is still very small in relation to previous accommodatons which has no window in the living space, she feels very satisfied. One factor for her satisfaction is that the seats in the living space are next to the window (Figure 8) which allows daylight to reach all the seats. Additionally, the window is facing west, which allows enough daylight in the afternoon. Therefore, in future research on this topic, there should be a consideration of variable daylight calculations (i.e. the whole living space and for the seating area only) in order to determine if there are variations in daylight levels that equate to satisfaction levels.
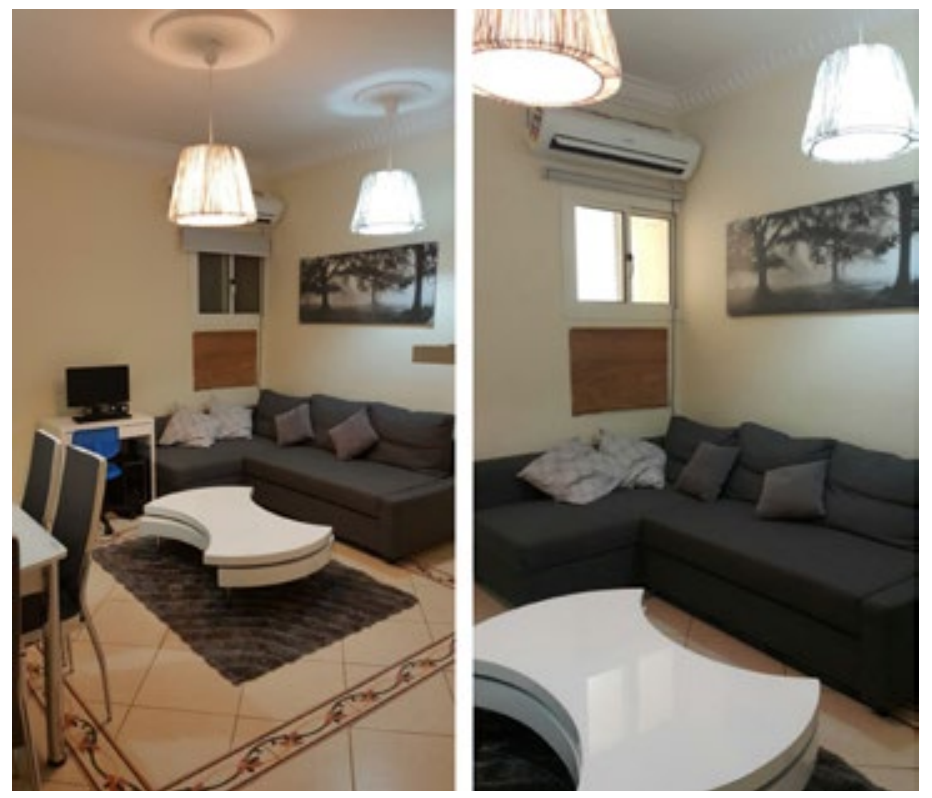

Figure 8. Small window facing road in third floor flat.

Most particpants share two main reasons for non-satisfaction, which are lack of daylight and small rooms. Bahammam (1998) argues that Saudi houses are divided into two sections - the family section and the guest section. This is intended to provide a maximum level of privacy. $\mathrm{He}$ also confirms that Saudi houses are the biggest compared to many other countries. The majority of participant aged 30-50 claim that the reception area is big but it is rarely used. They want the living space to be the biggest part of the flat as it is the most used part. The study shows 
a shift in spatial use in the past decades which differs with the findings of Bahammam. In 1998, modern architecture and modern lifestyle had existed for 20 years but many changes started to take place during the next 20 years to the current study in terms of the economy, technology, and others. For instance, the majority of participants discussed their current day activities as if they had little function. The reseach data shows this when comparing the answers of female of different ages.

On the other hand, participants in roof flats expressed their satisfaction with the daylight level. They mentioned that they do not like to leave home. One of the participant who lives on the top floor mentioned: "I feel so happy during the morning when I see sunlight. It provides me with psychological comfort during the day". They enjoy the morning in the living space and feel relaxed as shown in Figure 9. While the top floor location exposes the resident to the gaze of neighbours, this does not seem to be a factor for this individual. Another participant living on the top floor asked her husband to design a big window facing the roof as shown in Figure 10 as she is concerned about being seen by neighbours. She relies on this window to provide daylight as it is transparent and facing the northern sky with diffused light. The side window facing the east is frosted and covered with a curtain due to the direct morning sun.

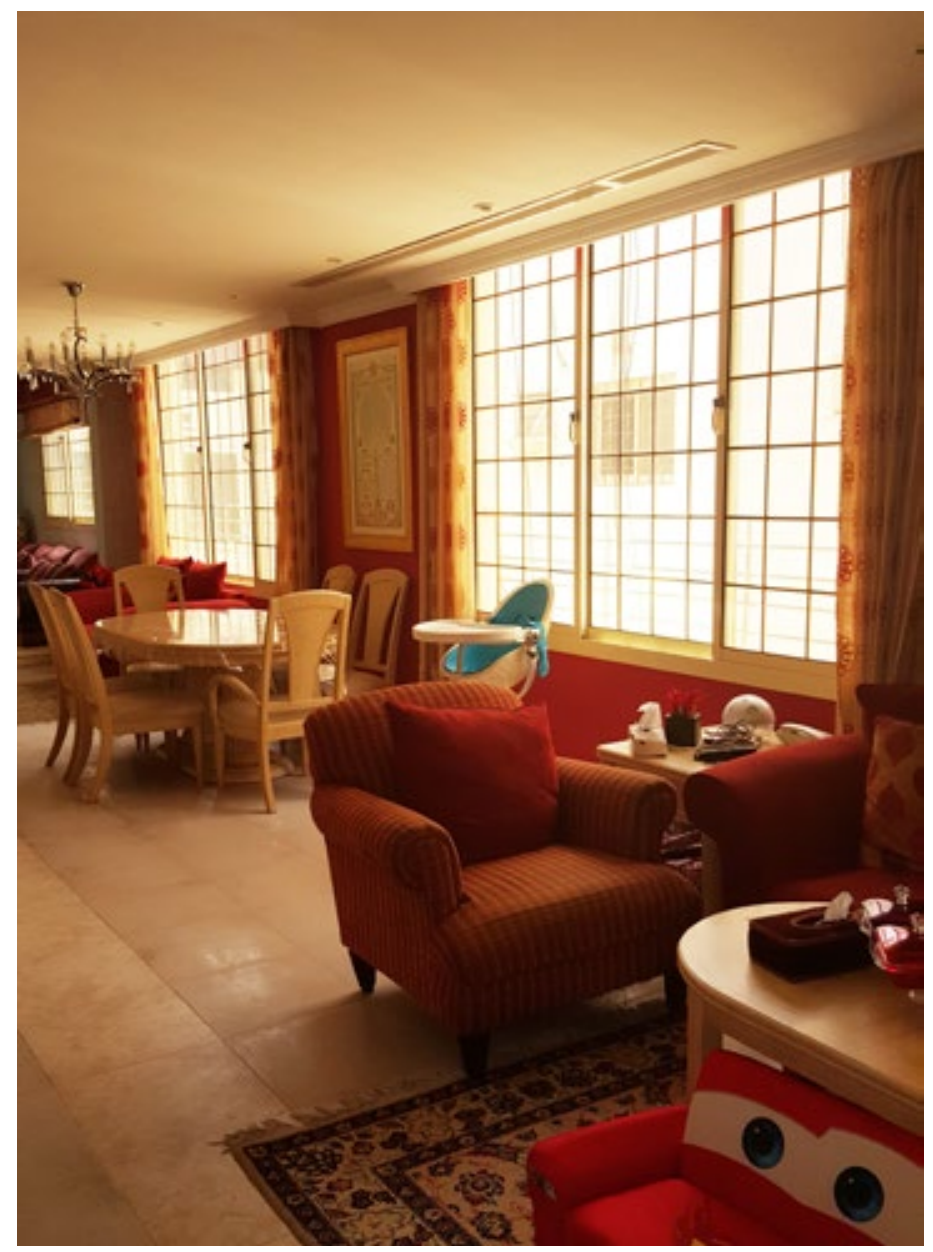

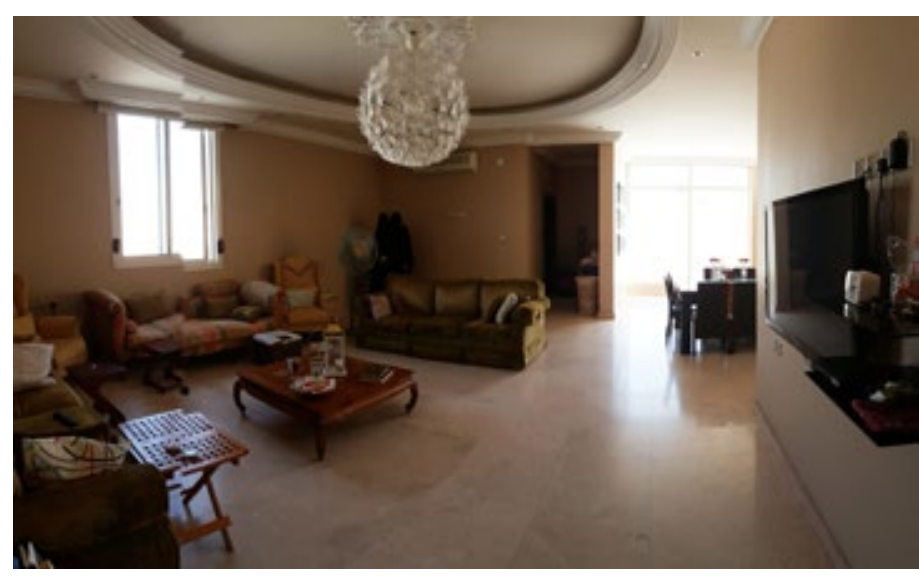

Figure 10. Roof flat with window facing roof.

\section{FEMALES' RIGHTS IN CHOOSING HOME}

According to Ward (2011)"While building Shape human Behaviour, Human decisions shape buildings" (p.4). This shows that home users decisions should be considered when designing a home. Data analysis from interviews shows that the majority of participants complain that no one cares about their decision, not even their husbands. Since their husbands are the ones who pay the rent, they think that they have the right to choose a flat that suits their budget not the females' needs. Six participants did not have the chance to choose their flats since they are married and it is the husband decision as shown in Table 7. This shows that men control flat choice in Saudi culture since according to the religion and culture, the man is responsible for providing his family with what they need. This is part of his religious duty (Aleid 2006).

If a husband does not rent a flat, it means he lives in a flat in his family building for free as shown in Table 8. This is true especially for those who live in their parents' buildings since they do not pay rent. This shows that window location is an important element that should be considered when locating windows and dividing rooms in a flat. For instance, the bedroom is for sleep, and the guest area is used at night. These two sides should be located in an area from which daylight can be blocked while the living area window should be facing an open space like a street.

\begin{tabular}{|c|c|c|c|c|c|}
\hline & $\begin{array}{l}\text { Age } \\
50-59\end{array}$ & $\begin{array}{l}\text { Age } \\
40-49\end{array}$ & $\begin{array}{l}\text { Age } \\
30-39\end{array}$ & $\begin{array}{l}\text { Age } \\
20-29\end{array}$ & $\begin{array}{l}\text { Total } \\
{[23]}\end{array}$ \\
\hline Married & 3 & 2 & 7 & 4 & 16 \\
\hline Widow & 1 & 0 & 0 & 0 & 1 \\
\hline Divorced & 0 & 2 & 0 & 0 & 2 \\
\hline Single & 0 & 0 & 2 & 2 & 4 \\
\hline
\end{tabular}

Table 7. Participant marital status.

Figure 9. Roof flat. 


\begin{tabular}{|c|c|c|c|c|c|}
\hline & $\begin{array}{l}\text { Age } \\
50-59\end{array}$ & $\begin{array}{l}\text { Age } \\
40-49\end{array}$ & $\begin{array}{l}\text { Age } \\
30-39\end{array}$ & $\begin{array}{l}\text { Age } \\
20-29\end{array}$ & $\begin{array}{l}\text { Total } \\
{[23]}\end{array}$ \\
\hline Rent & 3 & 1 & 3 & 5 & 12 \\
\hline Own & 1 & 1 & 3 & 0 & 5 \\
\hline Family building & 0 & 2 & 3 & 1 & 6 \\
\hline
\end{tabular}

\section{REFERENCES}

Abu-Ghazzeh, Tawfiq M. 1994. "Built form and religion: underlying structures of Jeddah Al-Qademah." Traditional Dwellings and Settlements Review. 11:49-59.

Abukalid, F. 2004. "Women's rights and duties in the family and society between customs and traditions and between Shari'a provisions." National Dialogue Conference, Almadinah Almonawarah.

Table 8. The number of women according to flat payment type

\section{CONCLUSION}

From the data analysed in this study, it emerged that the interviewed female are not satisfied with the level of daylight in their flats in general and in the living room specifically. It shows that individual, cultural and gendered needs of participant regarding the design of rental flats is not considered. The study found that lightwell windows should not be located in living space at all as it does not provide adequate daylight and creates issues with acoustic exposure. This lack of daylight lead to psychological and physical illness for some women as they spent long time in this space. It is found that the majority of participants do not recommend roshan window as a solution for the current situation. They recommend a solution that provide them with enough daylight and privacy in contemporary design. The research exposes that building codes regarding window design and daylight need more study as the current code of a two meter gap between buildings creates an issue instead of solving a situation. Even though there is a special department in the Saudi Council of Engineers held by women, this department does not seem to be addressing the needs of women in their daily lives.

This work also provides a different point of view with regard to existing studies on daylight which claim that a light well or small gap between buildings provides enough daylight for interior spaces. Data was limited to female answers in interviews, a procedure that is difficult due to cultural issues of privacy that challenges the acceptance of the interview as a research strategy. The major limitation of this study is the small sample size, restricted due to the fact that interviews are not broadly accepted by females in the country, especially if they involve direct visits to the house. Further research needs to include a wider selection of participants (male, female, youth and children) from different cities in the Kingdom of Saudi Arabia.

Adas, Adnan Abbas. 2013. "Wooden Bay Window (Rowshan) Conservation in Saudi-Hejazi Heritage Buildings." ISPRS-International Archives of the Photogrammetry, Remote Sensing and Spatial Information Sciences 1 (2):7-11. https://doi.org/10.5194/ isprsarchives-XL-5-W2-7-2013

Al-Jamea, May. 2014. "Towards social and cultural sustainability in the designs of contemporary Saudi houses." Int J Sustain Hum Dev 2 (1):35-43.

Al-Jawahrah, Hani. 2002. From vernaculer architecture to skycarpers: $A$ critical review of major architecture trends in the Kingdom of Saudi Arabia Alehsaa, Saudi Arabia: King Fahad University.

Al-Murahhem, Faredah Mohsen. 2008. "Behind the Roshan: Visualising the Roshan as an architectural experience in traditional domestic interiors." PhD thesis, University of Brighton.

Al Surf, Muhammed, Connie Susilawati, and Bambang Trigunarsyah. 2012. "Analyzing the literature for the link between the conservative Islamic culture of Saudi Arabia and the design of sustainable housing." Proceedings of 2nd International Conference Socio-Political and Technological Dimensions of Climate Change, Malaysia.

Alawad, Abeer. 2017. "Using the Architectural Style of heritage Buildings as a Tool to Avoid Health risks-An Analytical Study of Rowshan in Traditional Houses in the City of Jeddah." Procedia Environmental Sciences 37:604-613. https://doi. org/10.1016/j.proenv.2017.03.047

Aleid, N. 2006. Women Rights in Prophit Sunnah. Riyadh, Saudi Arabia.: Prince Norah University.

AlHumaidi, Waleed. 1996. "The dilemma of regulation privacy: planning regulations, privacy and house form; The case study of low-density single-family dwellings in Saudi Arabia." PhD thesis, University College London.

Alitany, Ayman, Ernest Redondo, and Adnan Adas. 2014. "A new methodology for a detailed $3 \mathrm{~d}$ modeling and documentation of the complex architectural heritage elements: A feasibility and case study of wooden projected window" the Roshan" in the historical city of Jeddah." Ega-Revista De Expresion Grafica Arquitectonica (24):176-187.

Alshaibani, KA. 2000. "Window to internal surfaces as an indicator for internal illuminance." Proceedings of the World Renewable Energy Congress., Brighton, UK. https://doi.org/10.1016/ B978-008043865-8/50124-0

Alsuwaida, Abdulkareem O, Yousef M Farag, Abdulla A Al Sayyari, Du- 
janah H Mousa, Fayez F Alhejaili, Ali S Al-Harib, Abdulrahman A Housawi, Bharati V Mittal, and Ajay K Singh. 2013. "Prevalence of vitamin D deficiency in Saudi adults." Saudi medical journal 34 (8):814-818.

Alzoubi, Hussain H, and Amneh H Al-Zoubi. 2010. "Assessment of building façade performance in terms of daylighting and the associated energy consumption in architectural spaces: Vertical and horizontal shading devices for southern exposure facades." Energy Conversion and Management 51 (8):15921599. https://doi.org/10.1016/j.enconman.2009.08.039

Asfour, Khaled. 1998. "Cultural crisis." The Architectural Review 203 (1213):52-60.

Bahammam, Ali. 1998. "Factors which influence the size of the contemporary dwelling: Riyadh, Saudi Arabia." Habitat International 22 (4):557-570. https://doi.org/10.1016/S01973975(98)00018-6

Baker, N, and K Steemers. 2002. "Daylight design of buildings, part 3chapter 11." In. London: James \& James.

Baker, Nick V, Aldo Fanchiotti, and Koen Steemers. 2013. Daylighting in architecture: a European reference book: Routledge.

Batterjee, Sara Adel. 2010. "Performance of shading device inspired by traditional hejazi houses in Jeddah Saudi Arabia." Master Thesis, The British University in Dubai.

Benjamin, Kathleen, and Tam Truong Donnelly. 2013. "Barriers and facilitators influencing the physical activity of Arabic adults: A literature review." Avicenna:8. https://doi.org/10.5339/ avi.2013.8

Boubekri, Mohamed. 2008. Daylighting, architecture and health. London: Routledge.

Cammarano, Silvia, Anna Pellegrino, Valerio Roberto Maria Lo Verso, and Chiara Aghemo. 2015. "Assessment of daylight in rooms with different architectural features." Building Research \& Information 43 (2):222-237. https://doi.org/10.1080/096132 18.2014.922359

Charmaz, Kathy. 1990. “Discovering'chronic illness: Using grounded theory." Social science \& medicine 30 (11):1161-1172. https://doi.org/10.1016/0277-9536(90)90256-R

Christie, Floor TE, and Linda Mason. 2011. "Knowledge, attitude and practice regarding vitamin $D$ deficiency among female students in Saudi Arabia: a qualitative exploration." International journal of rheumatic diseases 14 (3):e22-e29.

Creswell, J. 1998. Qualitative inquiry and research design: Choosing among five traditions. Thousand Oaks, CA: Sage Publications.

Crisp, VHC, P Littlefair, I Cooper, and G McKennan. 1988. Daylighting as a passive solar energy option: An assessment of its potential in non-domestic buildings. Garston, CRC: Building Research Establishment Report.

Dahlan, A, and A Mohamed. 2010. "Urban legislation and its impact on an environmental of contemporary architecture in Saudi Arabia: Study of building regulations in the city of Jeddah as an example." Journal of Engineering Sciences, Assiut University 38 (1):285 -304.

Das, Aparna, and Saikat Kumar Paul. 2015. "Artificial illumination during daytime in residential buildings: Factors, energy implications and future predictions." Applied Energy 158:65-85. https:// doi.org/10.1016/j.apenergy.2015.08.006

Edgar, Goell, and Nisreen Lahham. 2008. "A Future Vision for Sustainable Egyptian Cities, Lessons Learned from the International Experience." Architecture... Urbanism \& Time, Vision for the Future, proceedings of ARUP.

Edwards, L, and Paul A Torcellini. 2002. A literature review of the effects of natural light on building occupants. Golden, Colorado: National Renewable Energy Laboratory Golden.

Elamin, Abdallah M, and Katlin Omair. 2010. "Males' attitudes towards working females in Saudi Arabia." Personnel Review 39 (6):746-766. https://doi.org/10.1108/00483481011075594

Freewan, AA, Li Shao, and S Riffat. 2008. "Optimizing performance of the lightshelf by modifying ceiling geometry in highly luminous climates." Solar Energy 82 (4):343-353. https://doi. org/10.1016/j.solener.2007.08.003

Freewan, Ahmed A. 2010. "Maximizing the lightshelf performance by interaction between lightshelf geometries and a curved ceiling." Energy Conversion and Management 51 (8):1600-1604. https://doi.org/10.1016/j.enconman.2009.09.037

Freewan, Ahmed A. 2015. "Developing daylight devices matrix with special integration with building design process." Sustainable Cities and Society 15:144-152. https://doi.org/10.1016/j. scs.2014.11.003

Freewan, Ahmed AY, Anne A Gharaibeh, and Monther M Jamhawi. 2014. "Improving daylight performance of light wells in residential buildings: Nourishing compact sustainable urban form." Sustainable Cities and Society 13:32-40. https://doi. org/10.1016/j.scs.2014.04.001

Gamboa, John. 2008. "City Expanding to The Desert Horizon: Riyadh's problem of explosive growth and urban sprawl." Geography 554:7-14.

Ghisi, Enedir, and John A. Tinker. 2005. "An Ideal Window Area concept for energy efficient integration of daylight and artificial light in buildings." Building and Environment 40 (1):51-61. doi: http://dx.doi.org.idpproxy.reading.ac.uk/10.1016/i.buildenv.2004.04.004.

Goell, E. 2007. "Becoming Sustainable: Suggestions for Local Sustainability Initiatives." Thesis, Federal Education and Networking Congress for Local Sustainability Initiatives, , Federal Ministry for the Environment.

Gou, Zhonghua, Stephen Siu-Yu Lau, and Feng Qian. 2013. “Comparison of mood and task performance in naturally-lit and artificiallylit environments." Indoor and Built Environment 24 (1):2736. https://doi.org/10.1177/1420326X13507792

Gul, Mehreen S, and Sandhya Patidar. 2015. "Understanding the energy consumption and occupancy of a multi-purpose academic 
building." Energy and Buildings 87:155-165. https://doi. org/10.1016/j.enbuild.2014.11.027

Hariri, Majdi Mohammed. 1991. "Roshan Design and its Imortance for the Residence. ." Umm Al-Qura 3 (5):175-237.

Hashim, Ahmad Hariza, and Zaiton Abdul Rahim. 2010. "Privacy and housing modifications among Malay urban dwellers in Selangor." Pertanika Journal of Social Science and Humanities 18 (2):259-269.

Idris, Mahmoud M. 2001. "Assessment of University Staff Flats in Riyadh Based on Judgement Made by Their Users." Arch \& Plan $13(1): 1-22$.

Jackson, Laura E. 2003. "The relationship of urban design to human health and condition." Landscape and urban planning 64 (4):191-200. https://doi.org/10.1016/S0169-2046(02)00230$\mathrm{X}$

Khodeir, Mamdouh, Magdy Shamy, Mansour Alghamdi, Mianhua Zhong, Hong Sun, Max Costa, Lung-Chi Chen, and Polina Maciejczyk. 2012. "Source apportionment and elemental composition of PM 2.5 and PM 10 in Jeddah City, Saudi Arabia." Atmospheric pollution research 3 (3):331-340. https://doi. org/10.5094/APR.2012.037

Kim, Gon, and Jeong Tai Kim. 2010. "Healthy-daylighting design for the living environment in apartments in Korea." Building and Environment 45 (2):287-294. https://doi.org/10.1016/j.buildenv.2009.07.018

Kreith, Frank, and D Yogi Goswami. 2016. Energy management and conservation handbook: CRC Press. https://doi. org/10.1201/9781315374178

Kristl, Živa, and Aleš Krainer. 1999. "Light wells in residential building as a complementary daylight source." Solar Energy 65 (3):197206. https://doi.org/10.1016/S0038-092X(98)00127-3

Kubba, Sam. 2012. Handbook of green building design and construction: LEED, BREEAM, and Green Globes: Butterworth-Heinemann.

Kuhlmann, Dörte. 2014. Gender studies in architecture: space, power and difference: Routledge.

Kultermann, Udo. 1999. Contemporary architecture in the Arab states: renaissance of a region. New York McGraw-Hill Professional Publishing.

Lam, William. 1992. Perception and Lighting as Formgiver for Architecture. New York: Van Nostrand Reinhold.

Lee, Yun-Suk, and Linda J Waite. 2005. "Husbands' and wives' time spent on housework: A comparison of measures." Journal of Marriage and Family 67 (2):328-336. https://doi. org/10.1111/j.0022-2445.2005.00119.x

Littlefair, PJ. 1991. Site Layout Planning for Daylighting and Sunlighting A Guide to Good Practice. Watford, UK: Building Research Establishment.

Mason, Mark. 2010. "Sample size and saturation in PhD studies using qualitative interviews." Forum Qualitative Sozialforschung/ Forum: Qualitative Social Research, Berlin.

McMullan, Randall. 2012. Environmental science in building. London, UK: Palgrave Macmillan.

Mishal, AA. 2001. "Effects of different dress styles on vitamin D levels in healthy young Jordanian women." Osteoporosis international 12 (11):931-935. https://doi.org/10.1007/s001980170021

Mofti, Farooq A, and Salah Aldin A Balto. 2013. "Lessons To Be Learned From A Comparative Evaluation Of The Traditional Towns of Riyadh A Jeddah In Saudi Arabia." Passive and Low Energy Architecture: Proceedings of the Second International PLEA Conference, Crete, Greece, 28 June-1 July 1983.

Mohelnikova, Jitka. 2010. "Comparative study of window glass influence on daylighting in an open-plan office." LEUKOS 7 (1):3747.

MOJ, Municipility of Jeddah. 2015. "Residential Buildings' Rules." https://www.jeddah.gov.sa/Business/LocalPlanning/BuildingRegulations/index.php, accessed 9.

Mortada, Hisham. 2003. Traditional Islamic principles of built environment. New York: Routledge.

Naeem, Zahid, AbdulRahman AlMohaimeed, Fawzy Khalil Sharaf, Hisham Ismail, Faiza Shaukat, and SN Bazmi Inam. 2011. "Vitamin D status among population of Qassim region, Saudi Arabia." International journal of health sciences 5 (2):116.

North, Peter, and Harvey Tripp. 2009. CultureShock! Saudi Arabia: A Survival Guide to Customs and Etiquette. Singapore: Marshall Cavendish International Asia Pte Ltd.

Opoku, Robert A, and Alhassan G Abdul-Muhmin. 2010. “Housing preferences and attribute importance among low-income consumers in Saudi Arabia." Habitat international 34 (2):219227. https://doi.org/10.1016/j.habitatint.2009.09.006

Othman, Zulkeplee, Rosemary Aird, and Laurie Buys. 2015. "Privacy, modesty, hospitality, and the design of Muslim homes: A literature review." Frontiers of Architectural Research 4 (1):1223. https://doi.org/10.1016/j.foar.2014.12.001

Parmar, Parthraj. 2016. "General Well-Being of Students and Professionals in the Field of Performing Arts in Relation to Gender and Experience." The International Journal of Indian Psychology $3(4): 55-82$.

Phillips, Derek. 2004. Daylighting: natural light in architecture. England: Routledge.

Salama, Ashraf M. 2006. "A lifestyle theories approach for affordable housing research in Saudi Arabia." Emirates Journal for Engineering Research 11 (1):67-76.

Salloum, Ashraf. 2013. "“El Rawashin” of Jeddah Saudi Arabia." Passive and Low Energy Architecture: Proceedings of the Second International PLEA Conference, Crete, Greece.

Samuels, W. 2010. "performance of permanently an investigation of mashrabiya for use with in the Gibson Dessert." Master The- 
sis, Victoria University of Wellington

Shatwan, A, and S Carta. 2017. "Privacy and Home Design in Jeddah Between Vernacular and Modern Architecture." International Architecture and Urban Studies Conference House \& Home, Istanbul.

Siddiqui, Aisha M, and Hayat Z Kamfar. 2007. "Prevalence of vitamin $D$ deficiency rickets in adolescent school girls in Western region, Saudi Arabia." Saudi medical journal 28 (3):441-444.

Statistics, Bureau of Labour. 2017. AMERICAN TIME USE SURVEY. United States of America: Department of Labour.

Susilawati, Connie, and Muhammed Al Surf. 2011. "Challenges facing sustainable housing in Saudi Arabia: a current study showing the level of public awareness." The 17th Pacific Rim Real Estate Society Conference, Bond University.

Syed, Jawad, Edwina Pio, Romie Frederick Littrell, and Andy Bertsch. 2013. "Traditional and contemporary status of women in the patriarchal belt." Equality, Diversity and Inclusion: An International Journal 32 (3):310-324. https://doi.org/10.1108/ EDI-12-2012-0122

Szokolay, Steven V. 2008. Introduction to Architectural Science. Milton Park, Abingdon: Routledge.

Vischer, Jacqueline. 1989. Environmental quality in offices. Van Nostrand Reinhold, New York: John Wiley \& Sons Inc.

Ward, Peter. 2011. A history of domestic space: privacy and the Canadian home. British Columbia: UBC Press.

Zamberi Ahmad, Syed. 2011. "Evidence of the characteristics of women entrepreneurs in the Kingdom of Saudi Arabia: An empirical investigation." International Journal of Gender and Entrepreneurship 3 (2):123-143. https://doi. org/10.1108/17566261111140206

Figures and Tables References:

All Figures are Tables are copyright for the first author. 